\title{
Reforma da Previdência Social: simulações e impactos sobre os diferenciais de sexo*
}

\author{
Izabel Guimarães Marri** \\ Simone Wajnman*** \\ Mônica Viegas Andrade****
}

\begin{abstract}
Como reflexo da sua atuação diferenciada no mercado de trabalho (marcada pela menor atividade econômica e menores salários), as mulheres recebem, em média, aposentadorias menores do que os homens, são as principais recebedoras das pensões por morte (dos maridos) e constituem a maioria dos beneficiários do Benefício de Proteção Continuada - BPC. Ao mesmo tempo em que recebem menores benefícios médios, maior é a dependência econômica relativa das idosas dos benefícios previdenciários e dos rendimentos de outros membros da família em que vivem. O presente trabalho busca verificar como possíveis modificações nas regras de elegibilidade de aposentadorias, pensão por morte e BPC, frequentemente mencionadas por especialistas como necessárias ao equilíbrio orçamentário do Sistema de Previdência Social brasileiro, podem afetar as iniquidades de renda entre os sexos na velhice, incorporando mais uma dimensão relevante para a avaliação das propostas de reforma do sistema.
\end{abstract}

Palavras-chave: Previdência Social. Desigualdade de renda. Gênero.

\section{Introdução}

O contexto de envelhecimento populacional e elevada informalidade das relações de trabalho suscita a preocupação atual com a insolvência dos sistemas de pensão, no Brasil e em vários países do mundo, sugerindo a necessidade urgente de reformá-los. As propostas de reformas (ou as reformas já ocorridas), por meio da alteração de parâmetros (regras de elegibilidade e concessão de benefícios), ou da estrutura dos sistemas como um todo, têm como objetivos principais reduzir o desequilíbrio fiscal dos sistemas, torná-los atuarialmente mais justos e, consequentemente, mais atraentes para seus participantes e para as futuras coortes. Há, no entanto, um outro lado da questão, também de grande importância, que vem ganhando espaço no debate nacional e internacional: o caráter de proteção social dos sistemas aos grupos economicamente mais vulneráveis e como esta proteção é alterada com as reformas. Dentro deste tema, o presente estudo analisa o tratamento diferenciado por sexo para alguns benefícios pagos pela Previdência Social brasileira, a

\footnotetext{
* Artigo desenvolvido com o apoio da Fundação de Amparo à Pesquisa de Minas Gerais - Fapemig, através de bolsa de pós-doutorado concedida a Izabel G. Marri.

** Doutora em Demografia, pesquisadora do Cedeplar/UFMG.

*** Doutora em Demografia, professora associada do Departamento de Demografia da UFMG.

${ }^{* * * *}$ Doutora em Economia, professora associada do Departamento de Economia da UFMG.
} 
importância que têm na redução das desigualdades de renda de idosas e idosos e como uma possível reforma nas regras de concessão destes benefícios poderia afetar o diferencial nos rendimentos de homens e mulheres em idades avançadas.

Como já bem documentado em diversos trabalhos, apesar do aumento da participação das mulheres do mercado de trabalho brasileiro ao longo das últimas décadas e da redução dos diferenciais salariais observados entre os sexos, ainda são grandes as diferenças de gênero no mercado de trabalho e nas atividades domésticas. Mesmo que coortes mais jovens não experimentem incompatibilidade do trabalho doméstico com a atividade econômica devido à maternidade, como ocorria em décadas passadas, o efeito da presença dos filhos e do cuidado com a família reduz as oportunidades de emprego para as muIheres e as direciona para ocupações de pior qualidade, que oferecem jornadas de trabalho mais reduzidas e menor proteção previdenciária (SORJ, 2004 apud LAVINAS, 2005, p. 32).

Como reflexo da atuação diferenciada no mercado de trabalho, as mulheres recebem, em média, aposentadorias menores do que os homens e constituem a maioria dos beneficiários do piso previdenciário e do Benefício de Prestação Continuada da Assistência Social ao Idoso (BPC). Adicionalmente, a diferença entre os sexos na expectativa de vida ao nascer de 7,6 anos a favor das mulheres, em 2007, ou de 4,8 anos, aos 60 anos de idade, ${ }^{1}$ as torna as principais recebedoras das pensões por morte (dos maridos). A sobrevida média feminina, ao mesmo tempo em que é considerada um dos principais fatores que causam o desequilíbrio atuarial entre os sexos na Previdência Social, também indica que elas precisarão se manter, por um maior tempo de vida, numa idade em que os cuidados com a saúde são ainda mais caros.

Estudos mostram que, além de receberem menores benefícios previdenciários médios, maior é a dependência econômica relativa das mulheres acima de 60 anos destes benefícios e dos rendimentos de outros membros da família em que vivem (TURRA; MARRI; WAJNMAN, 2008), o que as torna um grupo mais vulnerável à perda de renda, caso sejam implementadas novas regras que restrinjam o valor dos benefícios.

Como forma de compensar o desequilíbrio entre os sexos no cuidado com os filhos e pela dupla jornada de trabalho, a Previdência Social brasileira mantém em seu desenho regras que privilegiam as mulheres. Trata-se das aposentadorias em idades mais jovens (bônus de cinco anos de idade) e com menor tempo de contribuição mínimo (bônus de cinco anos no tempo de contribuição) em relação aos homens. Estes privilégios, aliados à maior sobrevida feminina nas idades avançadas, reforçam o argumento de injustiça atuarial entre os sexos, constituindo-se em forte argumento contra a manutenção dos diferenciais nas regras. Além disso, há regras que, apesar de não serem específicas por sexo, como as pensões por morte, afetam em maior escala as mulheres e que, na comparação internacional, são consideradas benevolentes para um país com o nível de desenvolvimento econômico do Brasil e com graves problemas fiscais (GIAMBIAGI et al., 2004; TAFNER, 2007; ROCHA; CAETANO, 2008). Por isso, várias regras atualmente vigentes são alvo de críticas e sugestões de alterações num contexto de uma possível reforma do Sistema (GIAMBIAGI et al., 2004; TAFNER, 2007; GIAMBIAGI et al., 2007; GIAMBIAGI et al., 2007b).

O exercício efetuado neste trabalho busca verificar como algumas dessas modificações nas regras de elegibilidade aos benefícios poderiam afetar as iniquidades de renda entre os sexos na velhice, incorporando mais uma dimensão relevante para a avaliação das propostas de reforma do sistema. Adicionalmente aos efeitos na renda, procurou-se contrapor o potencial impacto fiscal e no orçamento da Previ-

\footnotetext{
1 Segundo dados do IBGE, a esperança de vida ao nascer era de 76,4 anos para as mulheres e de 69,1 anos para os homens. A esperança de vida aos 60 anos era de 22,6 e 19,4 anos para os dois sexos, respectivamente (BRASIL, 2007b).
} 
dência para cada uma das propostas de mudança frequentemente mencionadas como necessárias. Especificamente, as mudanças analisadas foram: aumento da idade mínima para aposentadoria por idade das mulheres; aumento do tempo de contribuição das mulheres; adoção de uma idade mínima para aposentadoria por contribuição de homens e mulheres; impossibilidade de se acumularem ambos os benefícios de aposentadoria e pensão (válido para os dois sexos); redução do valor das pensões de acordo com o número e idade dos filhos; e elevação da idade mínima para se requerer o benefício de amparo assistencial ao idoso (BPC), bem como redução do seu valor (para ambos os sexos).

A análise dos diferenciais de gênero nos sistemas de pensão é um tema extremamente complexo, pois coloca em cheque funções, em princípio, antagônicas, que coexistem nos sistemas de Previdência Social: a proteção social aos menos favorecidos financeiramente e a justiça atuarial, embutida na lógica de um seguro contra a redução da renda na velhice. Alguma proteção social é desejável, no sentido de impedir que pessoas com históricos laborais menos privilegiados, que não conseguem contribuir com o mínimo necessário para gerarem suas próprias aposentadorias na idade avançada, fiquem desamparadas do ponto de vista de renda. Ao mesmo tempo, o sistema deve preservar uma relação atuarial justa entre as contribuições efetuadas pelos trabalhadores e os benefícios que dele recebem ao se aposentarem, pois só assim este sistema se manterá atrativo ao longo do tempo, garantindo sua exequibilidade do ponto de vista orçamentário. Quanto maior o vínculo entre contribuições e benefícios, menor é a flexibilidade do sistema para transferências dos grupos mais privilegiados para os menos privilegiados financeiramente. Quais grupos devem receber e quais devem efetuar as transferências de renda no Sistema de Previdência e em qual medida esta transferência deve ser realizada são questões importantes, que precisam ser discutidas pela sociedade.

Neste trabalho, o estudo dos efeitos de uma possível reforma é feito somente do ponto de vista da proteção social, em que analisamos o nível de renda relativo de homens e mulheres, antes e pós-alterações em determinado ano. Na perspectiva atuarial, na análise que não considera o nível de renda de um dado período (ou ano), mas sim todas as contribuições e benefícios pagos e recebidos durante o ciclo de vida do indivíduo representativo de um determinado grupo, as mulheres têm maiores retornos do Sistema (ganhos atuariais) do que os homens. ${ }^{2}$ Elas contribuem relativamente por menos tempo (devido às regras diferenciadas por sexo que privilegiam as mulheres) e gozam, relativamente, por mais tempo dos benefícios recebidos (devido à maior sobrevida em relação aos homens). Nesta comparação, o maior retorno relativo auferido pelas mulheres é financiado pelas perdas dos homens, como demonstrado em vários trabalhos (ver, por exemplo, FERNANDES, 1994; WORLD BANK, 1995).

Assim, as análises da proteção social e da justiça atuarial indicam resultados opostos para o problema da desigualdade de gênero nos sistemas de pensão. No estudo aqui realizado, partimos do princípio de que as alterações analisadas têm como característica restringir o pagamento dos benefícios em tempo ou valor, ajustando contribuições efetuadas e benefícios recebidos. Se as mulheres são o principal grupo atingido com as mudanças, do ponto de vista atuarial as modificações devem reduzir seus ganhos. Isto posto, interessa-nos saber o que ocorrerá com o nível de renda das idosas, vis-à-vis a renda dos idosos, se as alterações forem implementadas.

Como metodologia, foram efetuadas microssimulações que permitiram criar uma base de microdados hipotéticos, na qual se atribuem a cada indivíduo benefícios previ-

\footnotetext{
2 Neste tipo de análise, dividem-se os participantes do sistema de Previdência Social em apenas dois grandes grupo (mulheres e homens, negros e brancos, coortes de nascimento de dois períodos distintos), sendo que os ganhos atuariais de um devem ser compensados por perdas do outro.
} 
denciários (e renda do trabalho) diferentes daqueles efetivamente recebidos. Como base de dados, utilizou-se a Pesquisa $\mathrm{Na}$ cional por Amostra de Domicílios - PNAD (IBGE) de 2006, além de dados administrativos de 2006 e 2007, empregados como parâmetros nas simulações efetuadas.

\section{Alterações nas regras de concessão dos benefícios}

As mudanças nas regras de acesso aos benefícios simuladas neste trabalho estão listadas a seguir. ${ }^{3}$ No Quadro 1, apresenta-se uma síntese destas alterações ao lado das regras vigentes em 2006. As mudanças aqui contempladas foram obtidas (total ou parcialmente) de trabalhos que analisam os crescentes déficits orçamentários da Previdência Social e que sinalizam possíveis mudanças para tornar o Sistema viável financeiramente e para ajustar regras consideradas benevolentes quando comparadas àquelas existentes em outros países com nível de desenvolvimento similar ao do Brasil (GIAMBIAGI, 2000; GIAMBIAGI et al., 2004; GIAMBIAGI et al., 2007; GIAMBIAGI et al., 2007b). São elas:

- aumento da idade mínima de aposentadoria por idade das mulheres para 63 anos, reduzindo o diferencial de idade entre homens e mulheres, dos atuais cinco para dois anos;

- aumento do tempo de contribuição das mulheres para 35 anos, eliminando a diferença entre os sexos;

- adoção de idade mínima de 61 anos, para aposentadorias por tempo de contribuição das mulheres;

- adoção de idade mínima de 65 anos, para aposentadorias por tempo de contribuição dos homens;
- redução do valor das pensões para $80 \%$ do valor atual, dependendo do número de filhos menores de 21 anos;

- impossibilidade de se acumularem benefícios de aposentadoria e pensão, sendo obrigatória a escolha entre o maior dos dois benefícios (para homens e mulheres);

- elevação da idade mínima para requerer o BPC do idoso, de 65 para 70 anos, e redução do valor do benefício para $75 \%$ do piso previdenciário.

É importante salientar que, na prática, qualquer alteração nas regras de concessão de benefícios deve ter um prazo para entrada em vigor, além de um prazo gradual de implementação para que a proposta seja aceita e aprovada pela população e pelo próprio governo. Para que sejam politicamente viáveis, as reformas precisam, primeiro, respeitar os direitos adquiridos dos atuais beneficiários, conservando para estes as regras atuais, posteriormente estabelecer as novas regras para os novos entrantes no sistema e, por fim, estabelecer regras de transição gradual entre as regras vigentes e aquelas estipuladas para os novos entrantes no sistema. Os trabalhos que propõem mudanças (como as simuladas neste exercício) sugerem que estas sejam implementadas num prazo entre 10 e 15 anos, alterando-se os parâmetros lentamente ao longo do tempo.

No exercício aqui proposto, no entanto, optou-se por estimar qual seria o impacto de alterações nas regras previdenciárias nos diferenciais de renda, vis-à-vis a potencial redução no déficit orçamentário, se as mudanças tivessem sido aplicadas no cenário (demográfico e econômico) de 2006 e, concluído o processo de transição, até que todos os beneficiários sob as re-

\footnotetext{
${ }^{3} \mathrm{O}$ critério de escolha das regras analisadas segue a relativa constância em que aparecem em trabalhos que analisam as razões para o crescente déficit na Previdência, seguindo do critério de exequibilidade operacional com os microdados da PNAD. Outras regras constantemente citadas como importantes no crescimento dos gastos da Previdência, não incluídas neste trabalho, são o vínculo do piso previdenciário ao salário mínimo e as diferenças nas regras para professores. Quanto ao vínculo do piso ao salário mínimo, um exercício preliminar com esta variável foi feito em Marri (2009). Devido aos resultados extremamente arbitrários para diferentes valores para o piso previdenciário, optamos por não incluí-lo neste trabalho.
} 
QUADRO 1

Regras atuais de acesso a alguns benefícios previdenciários e assistenciais e modificações analisadas

\begin{tabular}{|c|c|c|}
\hline Regra atual & \# & Modificação analisada \\
\hline \multicolumn{3}{|l|}{ Aposentadoria por idade } \\
\hline $\begin{array}{l}\text { Idade mínima } \\
\text { Mulheres: } 60 / 55 \text { anos (urbano/rural) } \\
\text { Homens: } 65 / 60 \text { anos (urbano/rural) }\end{array}$ & 1 & $\begin{array}{l}\text { Idade mínima } \\
\text { Mulheres: } 63 \text { anos (urbano) }\end{array}$ \\
\hline \multicolumn{3}{|l|}{ Aposentadoria por tempo de contribuição } \\
\hline \multirow{3}{*}{$\begin{array}{l}\text { Tempo mínimo de contribuição } \\
\text { Mulheres: } 30 \text { anos (urbano) } \\
\text { Homens: } 35 \text { anos (urbano) }\end{array}$} & 2 & $\begin{array}{l}\text { Tempo mínimo de contribuição } \\
\text { Mulheres: } 35 \text { anos (urbano) }\end{array}$ \\
\hline & 3 & $\begin{array}{l}\text { Idade minima } \\
\text { Mulheres: } 61 \text { anos }\end{array}$ \\
\hline & 4 & $\begin{array}{l}\text { Idade mínima } \\
\text { Homens: } 65 \text { anos }\end{array}$ \\
\hline \multicolumn{3}{|l|}{ Pensão por morte } \\
\hline \multirow{2}{*}{$\begin{array}{l}\text { Não há restrições em acumular os benefícios de } \\
\text { pensão e aposentadoria. } \\
\text { O valor do benefício corresponde a } 100 \% \text { do valor do } \\
\text { salário ou aposentadoria a que o(a) falecido(a) teria } \\
\text { direito em vida. }\end{array}$} & 5 & $\begin{array}{l}\text { Reduzir o valor das pensões para } 80 \% \text {, respeitando o } \\
\text { piso previdenciário, com aumento de } 10 \% \text { por cada filho } \\
\text { menor de } 21 \text { anos, atingindo o valor máximo de } 100 \% \text {. }\end{array}$ \\
\hline & 6 & $\begin{array}{l}\text { Manter a renda de pensão ou aposentadoria, a que for } \\
\text { maior. }\end{array}$ \\
\hline \multicolumn{3}{|l|}{ Amparo assistencial ao idoso } \\
\hline $\begin{array}{l}\text { Têm direito ao amparo assistencial os idosos a partir } \\
\text { de } 65 \text { anos de idade que não exerçam atividade re- } \\
\text { munerada, que não sejam beneficiários da previdên- } \\
\text { cia social e que comprovem renda mensal per capita } \\
\text { inferior a um quarto do salário mínimo (R\$ 75,00 em } \\
\text { set./2006). }\end{array}$ & 7 & $\begin{array}{l}\text { Idade mínima para requerer o benefício: } 70 \text { anos } \\
\text { Redução do valor do benefício: } 75 \% \text { do piso previdenciá- } \\
\text { rio (equivalente a } \mathrm{R} \$ 262,50 \text {, em setembro de } 2006 \text { ). }\end{array}$ \\
\hline
\end{tabular}

Fonte: Elaboração das autoras.

gras antigas estivessem fora do sistema. Esta opção deve-se à dificuldade de se estimarem, para a população projetada, as inúmeras possibilidades de mudanças na estrutura populacional atreladas a alterações macroeconômicas e comportamentais dos indivíduos no longo prazo e, consequentemente, à dificuldade de atribuir rendimentos aos indivíduos e às suas famílias para cada período projetado. Deve-se, então, ter em mente que as simulações referem-se a uma população hipotética, que detém todas as características demográficas e socioeconômicas do Brasil de 2006. Os resultados apurados neste exercício, apesar de não revelarem os números que serão de fato experimentados com a implementação das novas regras ao longo do tempo, são válidos na avaliação das políticas, na medida em que mostram tendências para as quais apontam cada uma das mudanças propostas. O exercício também é elucidativo quanto ao trade-off entre efeitos de redução de despesas previdenciárias e no nível de renda dos indivíduos.
Entre os critérios de concessão de aposentadorias em discussão no país e no mundo, talvez a mudança cujo efeito positivo nas contas do Sistema seja mais facilmente apreendido é a de elevação da idade mínima de aposentadoria para ambos os sexos. Elevar a idade mínima ou o tempo mínimo de contribuição necessário para requerer o benefício aumenta o tempo potencial de contribuição e reduz o tempo de gozo do benefício, melhorando as receitas de contribuição e diminuindo as despesas com benefícios pagos. Além disso, em um sistema atuarialmente justo, quanto maior for o tempo de contribuição, maiores devem ser os benefícios recebidos, sendo uma alternativa interessante também para quem os recebe.

No Brasil, especificamente, os argumentos de aumento da idade mínima de aposentadoria e do tempo mínimo de contribuição (para ambos os sexos) se baseiam no fato de o país apresentar, ao mesmo tempo, enorme déficit previdenciário e uma das idades de aposentadoria mais baixas do 
mundo. Esta situação é ainda mais clara quando se considera a aposentadoria por tempo de contribuição, em que os aposentados, sem limite mínimo de idade, podem se aposentar mais cedo do que os aposentados por idade e com maiores benefícios (ROCHA; CAETANO, 2008; GIAMBIAGI et al., 2004, entre outros). Além disso, como já citado, a diferença da idade mínima e do tempo de contribuição entre os sexos acarreta desequilíbrio atuarial entre os dois grupos, com ganhos para as mulheres.

A idade mínima para aposentadoria no Brasil, para aqueles que se aposentam por idade, é de 65 e 60 anos, para homens e mulheres urbanos, respectivamente, e $60 \mathrm{e}$ 55 anos, para homens e mulheres trabalhadores rurais, observando a carência de 180 meses de contribuição mensal para trabaIhadores urbanos, ou 180 meses de trabalho no campo para os rurais. Para aposentadoria pelo critério de tempo de contribuição, os homens devem contribuir por um mínimo de 35 anos e as mulheres por 30 anos, não havendo idade mínima requerida para aposentadorias integrais. Os professores dos níveis fundamental e médio gozam de um bônus de cinco anos para aposentadoria por tempo de contribuição, podendo requerê-la após 30/25 anos (homens/mulheres), desde que comprovem tempo exclusivo de docência em sala de aula (§ 8으, art. 201 da Constituição Federal e art. 56 da Lei n.으 8.213/91). Como resultado, a idade média de novas aposentadorias efetivamente concedidas por tempo de contribuição, em 2007, por exemplo, era de 54 anos, para os homens, e 51 anos, para as mulheres, e para a aposentadoria por idade correspondia a 66 e 62 anos, respectivamente (BRASIL, 2008).

$\mathrm{Na}$ comparação internacional, o Brasil constitui um dos poucos casos em que é possível se aposentar sem uma idade mínima. Mulheres e homens que se aposentam por tempo de contribuição no Brasil o fazem, em média, 9 e 8 anos mais jovens do que a média dos seus pares na América Latina (ou 11 e 10 anos mais jovens, respectivamente, do que seus pares da Organização para a Cooperação e Desenvolvimento EconômiCo - OCDE), com duração do tempo médio de gozo da aposentadoria dez anos maior (para os dois grupos de países e para ambos os sexos) (ROCHA; CAETANO, 2008, p. 19). Além da idade média mais baixa, só são elegíveis à aposentadoria por tempo de contribuição os trabalhadores formais (entendidos aqui como os que contribuem com a Previdência Social), que apresentam carreiras mais longas, com empregos mais estáveis e maiores salários, sendo claramente um benefício destinado às pessoas financeiramente privilegiadas, o que acentua o quadro de desigualdade de renda do país (ALÉM; PASTORIZA; GIAMBIAGI, 1996).

Com relação à aposentadoria pelo critério de idade mínima, na maioria dos países as idades de aposentadoria são iguais para homens e mulheres (como Alemanha, Canadá e México, 60 anos; EUA, 62 anos; Noruega, 67 anos), mas alguns mantêm a diferença entre os sexos (como Argentina, Chile e Áustria, 65 e 60 anos, e Bélgica, 65 e 64 anos, para homens e muIheres, respectivamente) (SSA, 2008). Os argumentos para a redução do diferencial entre os sexos, além de seguirem a tendência internacional, recaem sobre o peso orçamentário de manter as aposentadorias precoces das mulheres (GIAMBIAGI, 2000, p. 16) e dos ganhos atuariais que elas obtêm relativamente aos homens.

Quanto ao benefício de pensão por morte no Brasil, em sua grande maioria recebido pelas mulheres, não existe nenhum critério que restrinja sua elegibilidade: não há idade mínima nem máxima necessária; não requer carência contributiva; não está vinculado ao número de filhos tidos, muito menos à idade destes quando da morte do pai (ou da mãe); pode ser acumulado à aposentadoria e é equivalente a $100 \%$ do valor do benefício ou salário a que o segurado tinha direito antes de morrer. Por isso é considerado um dos mais benevolentes do mundo (GIAMBIAGI et al., 2007, p. 25; TAFNER, 2007, p. 9). Em 2007, as despesas com pensões por morte, no Brasil, corresponderam a $\mathrm{R} \$ 2.855$ milhões, equivalentes a $21 \%$ dos benefícios ativos totais pagos pelo INSS (BRASIL, 2007).

Tafner (2007) calcula quanto seria economizado no país, em 2004, se fossem aplicadas as regras de aposentadoria e 
pensão por morte vigentes em outros países. O autor mostra, por exemplo, que se fossem adotadas, no Brasil, as condições de elegibilidade das pensões da Finlândia, que combinam idade da viúva de 65 anos ou menos e a presença de um filho dependente no domicílio, apenas $15 \%$ dos benefícios atuais seriam mantidos, resultando em uma economia de $\mathrm{R} \$ 2,4$ bilhões mensais.

Dada a relevância dos gastos com as pensões e tomando como exemplo as diferenças existentes em outros países, propomos para este exercício a análise dos efeitos das seguintes alterações: redução do valor das pensões para $80 \%$, independentemente da idade do beneficiário, com aumento de $10 \%$ por cada filho menor de 21 anos, atingindo o valor máximo de $100 \%$; e manutenção da renda de pensão ou de aposentadoria, a que for maior.

Da mesma forma, as regras que regem o BPC do idoso também são constantemente citadas como passíveis de mudança. $O$ BPC é um benefício assistencial, integrante do Sistema Único da Assistência Social - Suas, pago pelo governo federal e, portanto, não entra no chamado déficit da Previdência Social, apesar de ser gerenciado (operacionalizado) pela Previdência Social. O BPC tem valor igual a um salário mínimo e é dado a todo deficiente físico, ou idoso de ao menos 65 anos de idade, que não receba nenhum benefício previdenciário e que comprove ter rendimento familiar per capita inferior a $1 \frac{1}{4}$ de salário mínimo. Exatamente porque a idade mínima do benefício ao idoso coincide com a idade mínima de aposentadoria para os homens e seu valor é igual ao piso previdenciário, ou seja, igual à aposentadoria da maioria dos aposentados, muitos trabalhadores contribuintes podem se ver desestimulados a contribuir com o Sistema, se suas expectativas são de que se qualifiquem para recebimento do benefício assistencial na velhice (GIAMBIAGI et al., 2004; CAMARGO; REIS, 2007; NEVES, 2008).

Neves (2008), ao analisar as várias combinações possíveis entre número de contribuições e idade de aposentadoria, definidas pela tabela do fator previdenciário, conclui que a existência do BPC desestimula apo- sentadorias próximas à idade de 65 anos, exatamente porque o esforço contributivo não seria refletido em uma aposentadoria maior do que o benefício assistencial. Além disso, Camargo e Reis (2007, p. 264) argumentam que o desincentivo à contribuição previdenciária proporcionado pelo BPC não só aumenta o grau de informalidade nas relações de trabalho, mas também afeta negativamente as contas do governo, reduzindo os impostos recolhidos sobre a folha de pagamentos.

Neste contexto, as mudanças nas regras de concessão do BPC, geralmente propostas, compreendem aumento da idade mínima e/ou redução do valor do benefício (GIAMBIAGI et al., 2004). Neste trabalho, consideramos 70 anos a idade mínima para recebimento do BPC (idade inicialmente proposta para este benefício) e reduzimos seu valor para $75 \%$ do piso previdenciário. Embora o que se pretenda com as mudanças no BPC seja o incentivo às contribuições e consequente redução das concessões do benefício assistencial, aqui será estimado o impacto direto dessa alteração sobre a renda dos idosos e não o efeito indireto (e pretendido) sobre as contribuições previdenciárias e seus desdobramentos.

\section{Metodologia}

Neste trabalho, efetuamos exercícios contrafactuais no nível micro (indivíduos), a partir dos quais foram atribuídos, a cada indivíduo, benefícios previdenciários e renda do trabalho diferentes daqueles observados, criando uma base de microdados hipotéticos. Nas simulações deste exercício, utilizaram-se os dados da Pesquisa Nacional por Amostra de Domicílios (PNAD) de 2006, levantamento amostral com representatividade para o Brasil, Grandes Regiões, Unidades da Federação e nove Regiões Metropolitanas. Foram também empregados dados disponíveis no sítio do Ministério da Previdência Social (acesso ao banco de dados Infologo, o Anuário Estatístico da Previdência Social-AEPS e o Boletim Estatístico da Previdência Social - BEPS) referentes a 2006 e 2007, quando necessários. 
O principal ponto positivo na metodologia das microssimulações, utilizada neste trabalho, é a possibilidade de mudar parâmetros de interesse para cada indivíduo da base de dados, sem a necessidade de atribuir valores médios para toda a população. Entre as principais limitações no método, tem-se que o resultado obtido será dependente da ordem em que são feitas as simulações, no caso de alterações simultâneas de mais de um parâmetro, pois o resultado de uma alteração é o ponto de partida para a alteração subsequente. Além disso, a metodologia apenas permite que se estime o efeito direto das modificações e não os efeitos secundários (ou comportamentais), que também devem ser modelados para serem captados nas simulações. Por exemplo, elevar a idade mínima de aposentadoria não terá efeitos secundários sobre a oferta de mão de obra de pessoas acima de certa idade, a menos que isto também seja determinado como uma modificação a posteriori.

No Brasil, entre os trabalhos que utilizam as microssimulações para avaliar impactos de políticas de Previdência Social, podem ser citados: Zylberstajn, Afonso e Souza (2005), que, com dados da PNAD 2001, verificam o custo de transição do modelo previdenciário atual para um sistema universal; Afonso, Souza e Zylberstajn (2006), que usam as microssimulações e dados da PNAD 2004 para estimar os impactos fiscais de variações no valor do salário mínimo e nas regras de aposentadoria pelo critério de idade mínima e tempo mínimo de contribuição de homens e mulheres; e Giambiagi et al. (2007c), que aplicam as alterações propostas em Giambiagi et al. (2004) no instrumental desenvolvido em Afonso, Souza e Zylberstajn (2006). Giambiagi et al. (2007c) projetam a população observada em 2005 até 2050 e simulam a trajetória no mercado de trabalho dos indivíduos, incluindo os novos entrantes no mercado de trabalho após este ano. Os resultados indicam que o aumento do piso previdenciário a taxas similares ao crescimento do PIB, ou à elevação da renda per capita (nesta ordem), constitui fator preponderante de ampliação do déficit do Sistema.
Com relação à dívida atuarial (calculada pelos fluxos de benefícios menos contribuições, trazidos a valores presentes de 2005), um conjunto de alterações proposto diminuiria a dívida de $40 \%$ a $60 \%$ (dependendo do cenário de crescimento do PIB e do salário mínimo), sendo que os fatores mais importantes para sua redução são a adoção de idade mínima de 64 anos para aposentadoria dos trabalhadores da ativa, a idade mínima de 67 anos para os novos entrantes no mercado de trabalho, o aumento da idade para obtenção do BPC para 70 anos, assim como a redução de $25 \%$ do seu valor. Medidas como o fim do bônus para as mulheres no fator previdenciário e a equalização do tempo de contribuição de mulheres e professores teriam impacto reduzido.

\section{Critérios e premissas adotados}

Os dados da PNAD, no que se refere aos beneficiários da Previdência Social, são restritos, pois não incluem informações sobre a idade com a qual a pessoa se aposentou, há quanto tempo está aposentada, por qual critério se aposentou (se por contribuição ou idade mínima), se é um aposentado pelo Regime Geral ou pelo Regime Próprio dos servidores públicos, se é um aposentado rural ou urbano, ou por quanto tempo a pessoa contribuiu antes de se aposentar. Sabe-se apenas que a pessoa já se encontrava aposentada na semana de referência da pesquisa, de forma que os dados revelam o estoque de aposentados em um determinado ano, resultado das várias regras e modalidades de aposentadorias que vigoraram até então. Além disso, os dados sobre aposentadorias, devido a erros de declaração, podem de fato se referir às pensões, e vice-versa, e a programas de transferências de renda, uma vez que os indivíduos que reportam seus rendimentos nem sempre sabem precisamente a origem do benefício. Isto posto, foram adotados algumas premissas e critérios para tornar possível o exercício das simulações. Por falta de espaço, estes critérios e premissas serão apenas citados, sendo que o detalhamento dos passos seguidos pode ser encontrado em Marri (2009, cap. 4) 
Adotou-se como premissa que apenas os aposentados que viviam na área urbana, segundo dados da PNAD, teriam as regras de aposentadoria modificadas, já que para os recebedores da aposentadoria rural há toda uma dinâmica específica de valores dos benefícios e regras de elegibilidade, diferentes dos aposentados urbanos. O pressuposto é que, embora os critérios de separação entre rural e urbano adotados pela PNAD e pela Previdência Social não sejam iguais, o critério adotado pela PNAD é uma proxy razoável para a separação, haja visto que caracteriza bem os dois grupos (rural e urbano) de aposentados, cuja distribuição concentra-se ao redor das idades mínimas de aposentadoria permitidas na lei, tanto para os trabalhadores rurais, quanto para os urbanos (MARRI, 2009, cap. 4).

Adotou-se também como critério a não separação dos aposentados entre os Regimes Jurídico Único (que atende aos funcionários públicos) e Geral de Previdência Social (dos trabalhadores do setor privado), visto que a tendência das reformas já ocorridas é de equalizar as regras de concessão dos benefícios de ambos os grupos, e que, no longo prazo, as diferenças tendem a ser reduzidas. Tomou-se o cuidado, no entanto, de excluir os aposentados cuja renda de aposentadoria fosse superior ao teto do RGPS (R\$2.801,82, em setembro de 2006), já que estes, pelo direito adquirido, não seriam afetados com as novas regras, evitando-se, assim, estimar redução nas despesas da Previdência e efeitos na renda dos beneficiários muito diferentes do que realmente seriam.

Como neste exercício são analisadas modificações nos critérios de aposentadoria segundo o tipo (por tempo de contribuição ou idade mínima), foi necessário separar as observações da amostra entre aposentados por contribuição, idade e invalidez.
Para tanto, utilizamos dados administrativos do RGPS (distribuição do número de aposentados e os valores médios das aposentadorias por tipo, segundo sexo e idade), que balizaram microssimulações aleatórias na separação dos aposentados nos três grupos. ${ }^{4}$

Uma vez separados, procedeu-se a alteração dos rendimentos. De forma sucinta, as pessoas que foram submetidas às alterações nas regras tiveram zerados os valores declarados das aposentadorias, ao mesmo tempo em que lhes foi devolvida uma renda do trabalho. A renda do trabalho que foi dada segue a premissa de que, postergando a idade mínima de aposentadoria ou aumentando o tempo de contribuição, os indivíduos mantêm sua condição de atividade e (des)ocupação que tinham antes de se aposentarem. Como a informação quanto ao passado da atividade econômica dos indivíduos não existe na PNAD, considerou-se que o grupo afetado pelas novas regras receberia rendas do trabalho, cuja distribuição fosse similar à distribuição das rendas do trabalho do grupo de economicamente ativos (e não aposentados), do mesmo sexo e grupo de idade. Seguindo este pressuposto, foi-lhes sorteada uma renda aleatória. Assumiu-se que os aposentados por tempo de contribuição, submetidos às novas regras, se manteriam ocupados após a simulação, e que os aposentados por idade mínima estariam economicamente ativos após a simulação, podendo estar ocupados ou desocupados (e receber renda igual a zero).

A simulação de aumento do tempo de contribuição das aposentadorias exigiu ainda o uso de parâmetros obtidos nos dados administrativos para transformar a informação de tempo de contribuição (não disponível na PNAD) em idade média estimada de aposentadoria. Os parâmetros uti-

\footnotetext{
4 É preciso ressaltar que a não separação dos aposentados nos dois regimes (RPPS e RGPS) e a utilização de informações do RGPS para separar os tipos de aposentados podem viesar os resultados, caso o diferencial por sexo seja diferente nos dois regimes. Entretanto, a quantidade superior de beneficiários do RGPS - 8 milhões de inativos e 4 milhões de pensionistas, contra 2 milhões de inativos e 1 milhão de pensionistas do RPPS (BRASIL 2007) - e a exclusão, nos dados da PNAD, daqueles beneficiários que recebiam valores acima do teto estabelecido por lei (estes, necessariamente do RPPS) devem minimizar a diferença entre os regimes, prevalecendo os diferenciais do RGPS, minimizando, consequentemente, vieses sobre os resultados estimados.
} 
lizados foram a idade média de concessão das aposentadorias ativas por contribuição e o tempo médio de serviço anterior ao início das aposentadorias.

Por fim, os dados sobre recebedores do BPC na PNAD também apresentam suas peculiaridades. A informação de recebimento do benefício obtida do Suplemento Transferência de Renda de Programas Sociais da PNAD 2006 está vinculada ao domicílio recebedor, e não ao próprio beneficiário. $\mathrm{O}$ benefício é declarado na variável em que outros rendimentos, como juros, aplicações e outras transferências de renda, também são declarados. Adiciona-se que não se sabe se o benefício refere-se ao auxílio ao idoso ou ao portador de deficiência, o que dificulta ainda mais a correta estimativa dos idosos que o recebem. ${ }^{5}$ Como o benefício pode ser dado a mais de uma pessoa no domicílio, sem que seu valor entre no cálculo da renda domiciliar per capita mínima para seu recebimento, a análise da renda familiar per capita, com os dados da PNAD, pouco informa sobre a possibilidade de o indivíduo ser ou não beneficiário do BPC. Assim, para estimar os idosos recebedores do benefício, foram identificados os domicílios receptores do BPC que possuíam um ou mais moradores com 65 anos ou mais de idade e, entre estes idosos, identificaram-se aqueles cuja variável "juros de caderneta de poupança e outras aplicações, dividendos e outros rendimentos" (v1273) fosse igual ou maior que um salário mínimo.

Segundo os dados da PNAD e a estratégia de identificação dos beneficiários adotada neste exercício, havia menos recebedores do BPC do idoso (558,6 mil, sendo $64 \%$ mulheres) do que apontam os dados administrativos (1.191 mil beneficiários, sendo $55,7 \%$ mulheres), indicando uma subenumeração dos BPCs do idoso na PNAD e maior participação das mulheres, relativamente às informações administrativas.

As mudanças propostas para este benefício são o aumento da idade mínima para 70 anos e a redução do valor do benefício em
$25 \%$. As simulações consistiram em zerar o valor dos benefícios dos beneficiários que tinham entre 65 e 69 anos e alterar para $\mathrm{R} \$ 262,5$ (decréscimo de $25 \%$ do valor vigente) os benefícios de todos os beneficiários. Como o resultado de uma simulação interfere no resultado da outra, foram feitos dois exercícios separados e, posteriormente, as duas simulações sequenciais, de forma que o valor reduzido do benefício foi dado apenas àqueles maiores de 70 anos de idade. Diferentemente das simulações com as aposentadorias, a premissa adotada para criar os contrafactuais dos recebedores de pensão e BPC é a de que não Ihes seriam atribuídas rendas do trabalho, já que, para isso, seriam necessárias premissas específicas para estes grupos, como nível de atividade econômica, (des)ocupação, informalidade e renda, o que foge do escopo deste trabalho.

Além dos efeitos relativos na renda de homens e mulheres, os resultados apresentados incluem uma estimativa bastante simplificada da potencial redução das despesas com benefícios e aumento da arrecadação, quando aplicável. A estimativa do percentual de redução das despesas com benefícios nada mais é do que a diferença entre o total dos benefícios recebidos antes e depois de cada simulação efetuada. Para fins de comparação entre as várias alterações de regras, a diferença no total de benefícios recebidos foi dividida pelo total de aposentadorias e pensões declaradas em 2006, e é apresentada como o equivalente a um percentual do total declarado com estes dois benefícios.

O potencial de aumento na arrecadação das alterações nas regras de aposentadoria foi estimado por meio da alíquota média de contribuição, calculada pelas alíquotas de contribuição informadas pelo Ministério da Previdência e pelas ocupações e renda de todos os trabalhos dos indivíduos, obtidas na PNAD. Esta alíquota média foi então multiplicada pelo somatório da renda do trabalho antes e após cada simulação e obtida a diferença.

\footnotetext{
${ }^{5}$ Em 2006, 51,6\% dos benefícios de amparo assistenciais ativos eram destinados aos portadores de deficiência e 48,4\% aos idosos (BRASIL, 2007).
} 


\section{Caracterização dos beneficiários afetados}

De acordo com os dados da PNAD 2006 e metodologias de identificação adotadas neste trabalho, $17 \%$ da população com 20 anos e mais seria afetada pelas mudanças nas regras de acesso a estes benefícios, sendo, em grande parte, idosos (pessoas com 60 anos e mais de idade). Separando-os por sexo, $13 \%$ dos homens e $21 \%$ das mulheres acima de 20 anos teriam suas rendas alteradas, o que significa um contingente muito maior de mulheres envolvido nas simulações: 4,3 milhões de mulheres e 2,5 milhões de homens.

A distribuição da população em quartis de renda utilizada neste trabalho baseia-se na renda individual total das pessoas acima de 20 anos, excluindo-se os aposentados cujas aposentadorias fossem superiores ao teto do RGPS. A distribuição por quartis divide a população em quatro grandes grupos de igual tamanho (q1, q2, q3 e q4) em ordem crescente de renda: em q1 (primeiro quartil) se situam os $25 \%$ mais pobres da população em estudo e, em q4, os $25 \%$ mais ricos. Quando identificadas as pessoas envolvidas nas simulações, observa-se que não há beneficiários em q1. Quase a metade das mulheres e dos homens afetados pelas mudanças das regras encontra-se em q2, e há maior proporção de homens do que de mulheres em q4.

O Gráfico 1 mostra a distribuição das mulheres por simulação e quartil de renda. Verifica-se que alterações nas regras afetam beneficiários situados em diferentes posições na distribuição de renda da população: aposentadoria e pensões atingem as mulheres que estão em melhor posição. O mesmo pode ser observado para o homens, no Gráfico 2. A comparação entre os dois gráficos mostra também que os homens afetados pelas simulações estariam em melhor posição relativa do que as mulheres, haja vista a maior participação daqueles em q4, tanto na simulação de duplo benefício (aposentadoria e pensão), quanto naquelas com o BPC.

\section{Resultados}

Os resultados das simulações foram analisados por meio do cálculo das rendas

GRÁFICO 1

Distribuição das mulheres afetadas em cada simulação, segundo quartis de renda individual Brasil - 2006

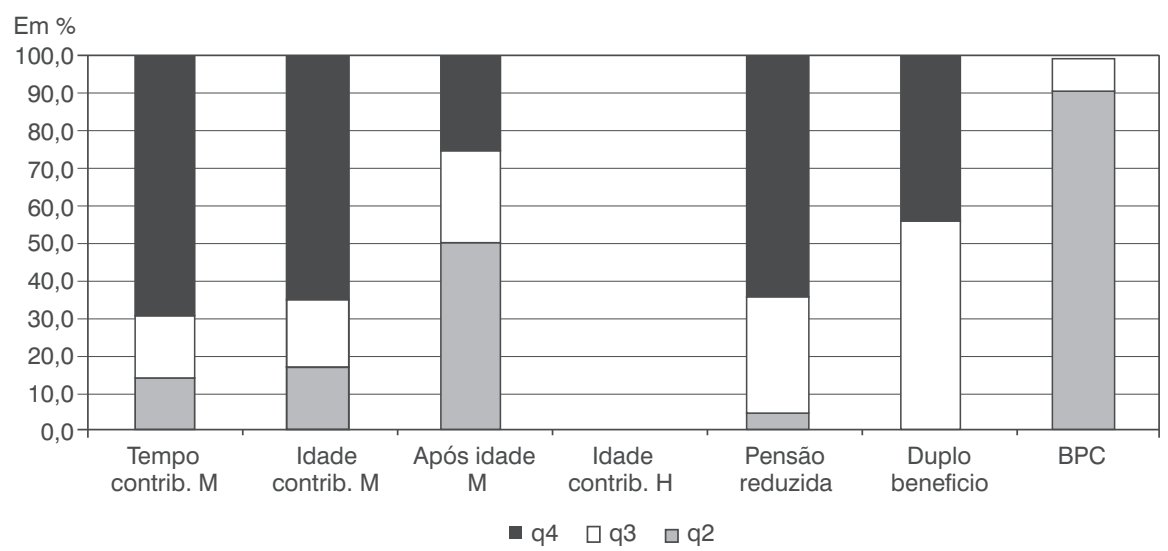

Fonte: IBGE. PNAD 2006.

Nota: Tempo contrib. $M$ = simulação de aumento no tempo de contribuição para aposentadoria por tempo de contribuição das mulheres; Idade contrib. M = simulação de adoção de idade mínima para aposentadoria por tempo de contribuição das mulheres; Apos idade $\mathrm{M}=$ aumento da idade mínima para aposentadoria por idade das mulheres; Idade contrib. $\mathrm{H}=$ simulação de adoção de idade mínima para aposentadoria por tempo de contribuição dos homens; Pensão reduzida = redução do valor da pensão de acordo com idade e número dos filhos; Duplo benefício = escolha do maior benefício entre aposentadoria e pensão; BPC = nova idade mínima e novo valor do benefício. 
GRÁFICO 2

Distribuição dos homens afetados em cada simulação, segundo quartis de renda individual Brasil - 2006

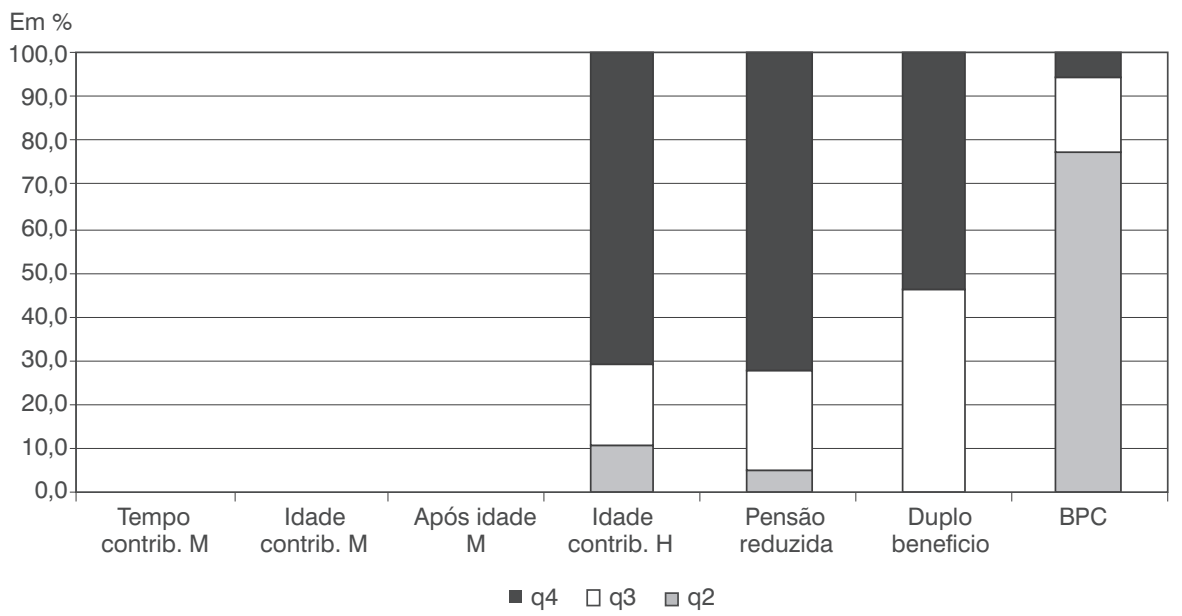

Fonte: IBGE. PNAD 2006.

Nota: Tempo contrib. $M$ = simulação de aumento no tempo de contribuição para aposentadoria por tempo de contribuição das mulheres; Idade contrib. M = simulação de adoção de idade mínima para aposentadoria por tempo de contribuição das mulheres; Apos idade $\mathrm{M}$ = aumento da idade mínima para aposentadoria por idade das mulheres; Idade contrib. $\mathrm{H}=$ simulação de adoção de idade mínima para aposentadoria por tempo de contribuição dos homens; Pensão reduzida = redução do valor da pensão de acordo com idade e número dos filhos; Duplo benefício = escolha do maior benefício entre aposentadoria e pensão; BPC = nova idade mínima e novo valor do benefício.

individuais médias dos grupos diretamente afetados pelas mudanças nas regras, pelas rendas individuais médias de grandes grupos etários (idosos - pessoas acima dos 60 anos - e adultos - população de 20 a 59 anos), pela renda familiar per capita e pela variação no percentual de pobres, sendo utilizado, como linha de pobreza, o valor de meio salário mínimo vigente na época da pesquisa. Adicionalmente, indicamos a potencial capacidade de aumento da arrecadação do Sistema (devido à elevação dos rendimentos do trabalho), quando aplicável, e de redução no pagamento de benefícios.

A renda individual foi considerada o indicador mais apropriado para a análise aqui desenvolvida, pelo fato de melhor indicar a independência (ou autonomia) financeira dos beneficiários em relação à própria Previdência Social e à renda de outros integrantes da família. A análise dos efeitos sobre a renda familiar per capita complementa a primeira análise, ao considerar as transferências de renda intrafamiliares, que tendem a equalizar o padrão de consumo dos membros de uma mesma unidade familiar.

A Tabela 1 resume a variação nas rendas observadas após as simulações. A Tabela 2 traz os possíveis efeitos nas despesas e na arrecadação do sistema.

As duas simulações para as aposentadorias por tempo de contribuição das muIheres - aumento do tempo de contribuição e introdução de idade mínima - atingiram, respectivamente, $5,7 \%$ e $11,5 \%$ do total de aposentadas (entre 40 a 55 anos e de 40 a 60 anos, respectivamente) de acordo com os registros da PNAD, sendo que a segunda simulação se sobrepõe à primeira. Efetuadas as simulações, a renda média individual aproximada de $\mathrm{R} \$ 1.550$ destes dois grupos se reduz em significativos $18 \%$, resultado das trocas dos altos rendimentos de aposentadoria, por rendimentos do trabalho.

Já a terceira simulação afetou um grupo distinto do primeiro: $3,9 \%$ do total de aposentadas em 2006, que tinham entre 60 e 62 anos e estavam aposentadas pelo critério de idade mínima. Este grupo possui 
TABELA 1

Efeitos das simulações sobre a renda individual média dos grupos, segundo simulação efetuada Brasil - 2006

\begin{tabular}{|c|c|c|c|c|c|c|}
\hline \multirow{2}{*}{ Simulação } & \multicolumn{2}{|c|}{ Pessoas atingidas } & \multirow{2}{*}{$\begin{array}{c}\begin{array}{c}\text { Variação na renda } \\
\text { do grupo afetado } \\
\text { pela simulação (\%) }\end{array} \\
\text { Homens Mulheres }\end{array}$} & \multicolumn{3}{|c|}{$\begin{array}{c}\text { Variação na renda da } \\
\text { população acima de } 60 \text { anos } \\
\text { e razão } \mathrm{M} / \mathrm{H}\end{array}$} \\
\hline & $\begin{array}{c}(\mathrm{em} \\
1.000)\end{array}$ & $\begin{array}{c}\% \text { de } \\
\text { mulheres }\end{array}$ & & $\begin{array}{c}\text { Homens } \\
(\%)\end{array}$ & $\begin{array}{l}\text { Mulheres } \\
\text { (\%) }\end{array}$ & $M / H$ \\
\hline
\end{tabular}

Relação renda das mulheres e dos

homens $(\mathrm{M} / \mathrm{H})$ antes das simulações

\begin{tabular}{|c|c|c|c|c|c|c|c|}
\hline $\begin{array}{l}\text { Aumento do tempo de contribuição } \\
\text { das mulheres }\end{array}$ & 429 & 100,0 & - & $-18,3$ & 0,0 & 0,0 & 0,62 \\
\hline $\begin{array}{l}\text { Introdução de idade mínima para } \\
\text { aposentadoria por tempo de contri- } \\
\text { buição das mulheres }\end{array}$ & 867 & 100,0 & - & $-18,7$ & 0,0 & $-0,1$ & 0,61 \\
\hline $\begin{array}{l}\text { Aumento da idade para } \\
\text { aposentadoria por idade das } \\
\text { mulheres }\end{array}$ & 295 & 100,0 & - & $-15,3$ & 0,0 & $-0,6$ & 0,61 \\
\hline $\begin{array}{l}\text { Introdução de idade mínima para } \\
\text { aposentadoria por tempo de contri- } \\
\text { buição dos homens }\end{array}$ & 1.992 & 0,0 & $-4,2$ & - & 0,6 & 0,0 & 0,61 \\
\hline Redução do valor da pensão & 2.138 & 92,0 & $-10,4$ & $-13,5$ & $-0,2$ & $-4,3$ & 0,59 \\
\hline Duplo benefício & 1.570 & 87,0 & $-31,5$ & $-34,5$ & $-1,0$ & $-7,9$ & 0,57 \\
\hline $\begin{array}{l}\text { BPC - aumento da idade mínima e } \\
\text { redução do valor }\end{array}$ & 559 & 64,0 & $-41,0$ & $-46,0$ & $-0,5$ & $-1,0$ & 0,61 \\
\hline
\end{tabular}

Fonte: Elaboração das autoras.

rendimentos médios menores $(R \$ 795)$ e seus rendimentos totais seriam reduzidos em 15\%. Pós-simulações, as mulheres (dos três grupos) passam a estar menos representadas no último quartil de renda e um pequeno grupo passa a ocupar o primeiro quartil.

Apesar do grande efeito na renda dos grupos afetados com as simulações, o efeito nas rendas médias do total de idosas é muito pequeno, devido ao baixo número relativo de beneficiárias afetadas. Consequentemente, a variação entre a renda das idosas e dos idosos (relação "M/H") se altera pouco (passa de 0,62 para 0,61), indicando pequeno aumento da disparidade de rendimentos entre os sexos (Tabela 1).

Introduzir uma idade mínima de aposentadoria dos homens de 65 anos afetaria $23,3 \%$ dos aposentados. Destes, 59\% ti- nham de 40 a 59 anos de idade e o restante possuía de 60 a 64 anos. Estes "ex"-aposentados, cujo rendimento médio é de $\mathrm{R} \$ 1.828$, teriam seus rendimentos médios reduzidos em $4,2 \%$, com a nova regra. Na distribuição entre quartis, haveria decréscimo da representação destes homens no quarto quartil, com aumento no terceiro quartil de renda. No agregado dos grandes grupos etários, os homens adultos teriam sua renda total diminuída em $2,9 \%$, reduzindo, consequentemente, a diferença na renda de homens e mulheres (aumentando, portanto, a razão $\mathrm{M} / \mathrm{H}$, que passa de 0,64 para 0,66 ). Para a população acima de 60 anos, a renda total dos homens se eleva ligeiramente e a razão $\mathrm{M} / \mathrm{H}$ passa de 0,62 para 0,61 .

Por outro lado, apesar dos pequenos efeitos sobre a renda dos grandes grupos etários, os impactos sobre a redução das 
TABELA 2

Redução nas despesas com benefícios e aumento da arrecadação da Previdência Social, segundo simulação efetuada

Brasil - 2006

Em porcentagem

\begin{tabular}{lcc}
\hline Simulação & Redução nas despesas & Aumento na arrecadação \\
\hline Aumento do tempo de contribuição das mulheres & 3,2 & 0,5 \\
$\begin{array}{l}\text { Introdução de idade mínima para aposentadoria por tempo } \\
\text { de contribuição das mulheres }\end{array}$ & 6,3 & 0,9 \\
$\begin{array}{l}\text { Aumento da idade para aposentadoria por idade das } \\
\text { mulheres }\end{array}$ & 1,1 & 0,2 \\
$\begin{array}{l}\text { Introdução de idade mínima para aposentadoria por tempo } \\
\text { de contribuição dos homens }\end{array}$ & 15,1 & 2,8 \\
$\begin{array}{l}\text { Redução do valor da pensão } \\
\text { Duplo benefício }\end{array}$ & 3,0 & 0,0 \\
\hline BPC - aumento da idade mínima e redução do valor & 4,8 & 0,0 \\
\hline
\end{tabular}

Fonte: Elaboração das autoras.

despesas após alteração nas regras de aposentadoria podem ser grandes (Tabela 2), principalmente com a introdução da idade mínima para as aposentadorias por tempo de contribuição das mulheres e dos homens. Estas duas simulações indicam que, caso estas regras estivessem valendo para 2006, as despesas com benefícios seriam menores, no equivalente a $6,3 \%$ e $15,1 \%$, respectivamente, do total dos benefícios de aposentadoria e pensão recebidos neste mesmo ano (74\% da redução total estimada, se todas as medidas fossem implementadas). Ao mesmo tempo, as medidas proporcionariam aumento da ordem de $0,9 \%$ e 2,8\% na arrecadação do sistema. Maior redução nas despesas e maior arrecadação na simulação feita para os homens são resultado de maiores aposentadorias, maiores rendas do trabalho, além de um número relativo bem maior de homens afetados pela medida.

Diante da necessidade de se reduzirem as despesas do sistema e torná-lo atuarialmente justo e dado o alcance das medidas em termos orçamentários, não parece razoável permitir aposentadorias por contribuição sem um limite mínimo de idade. A inexistência de idade mínima é privilégio de um grupo que se aposenta ainda jovem, com rendimentos maiores em comparação com a maioria dos aposentados. Além disso, quanto maior for o tempo de contribuição e a idade para a aposentadoria, maiores tendem a ser os valores dos benefícios a serem recebidos, o que reforça o argumento a favor da implementação das medidas.

Com relação ao aumento da idade mínima de aposentadoria das mulheres e ao fim da diferença de idade de aposentadoria entre homens e mulheres, pode-se dizer que, mesmo que a medida não surta grandes efeitos orçamentários na comparação com as demais medidas aqui estudadas, reduzir os diferenciais entre os sexos significa maior equidade no tratamento dos grupos pela Previdência Social. No entanto, também parece justo reconhecer que o trabalho de cuidado com a família ainda é função desempenhada, sobretudo, pelas mulheres, o que impede ou dificulta sua maior dedicação ao mercado de trabalho. Assim, a decisão sobre manter diferenciais de gênero na idade ou no tempo de contribuição para aposentadoria requer algum juízo de valor sobre reconhecer ou não, nas regras previdenciárias, as razões que levam as mulheres, em geral, a se dedicarem menos ao mercado de trabalho. Se os ganhos em esperança de vida obtidos por homens e mulheres permitem inegavelmente que se elevem as idades mínimas de aposentadoria 
para ambos os sexos, o diferencial entre elas ainda tem respaldo na necessidade de reconhecimento das diferentes funções exercidas pelas mulheres no cuidado familiar.

Posteriormente às simulações com as aposentadorias, foram efetuados os exercícios contrafactuais para os recebedores de pensão. Simulou-se como seria a renda dos pensionistas caso o valor do benefício fosse reduzido de acordo com o número e a idade dos filhos, ou se o beneficiário fosse impedido de acumular pensão e aposentadoria (duplo benefício), sendo obrigatória a manutenção do maior entre os dois benefícios.

Os beneficiários afetados pela primeira alteração (número de filhos menores de 18 anos) apresentam rendimento médio de $\mathrm{R} \$ 1.843$, para homens, e $\mathrm{R} \$ 1.542$, para mulheres. Estes rendimentos seriam reduzidos em 10,4\% e 13,5\%, respectivamente, e tanto os homens quanto as mulheres afetados perdem posição na distribuição de renda da população, reduzindo sua participação entre os 25\% mais ricos.

$\mathrm{Na}$ análise pelo agregado de grandes grupos etários, verifica-se maior queda relativa nos rendimentos médios das idosas (Tabela 1), o que aumenta o diferencial por sexo do rendimento entre os idosos, reduzindo a razão $\mathrm{M} / \mathrm{H}$ para 0,59 .

O segundo exercício eliminou o menor dos dois benefícios recebidos pelos "duplo-beneficiários". Os dados mostram que 2,3\% dos homens aposentados e 18\% das mulheres aposentadas recebiam também algum tipo de pensão. Entre os duplo-beneficiários, $87 \%$ eram mulheres e $20 \%$ referiam-se à população cujo local de residência era a área rural. A distribuição etária dos duplo-beneficiários era semelhante entre os dois sexos: $89 \%$ dos homens e $91 \%$ das mulheres possuíam 60 anos ou mais.

Considerando-se apenas o grupo de beneficiários envolvidos na simulação, seus rendimentos médios totais sofreriam queda de $31,5 \%$, para os homens, e $34,5 \%$, para as mulheres. A elevada redução no rendimento, adicionada ao grande contingente de mulheres afetado, representa queda de 7,9\% na renda média das idosas e de apenas $1 \%$ na dos idosos, aumentando ainda mais o diferencial de renda entre os sexos deste grupo de idade e reduzindo a razão $\mathrm{M} / \mathrm{H}$ para 0,57 . A proibição do duplo-benefício reduz a participação de ambos os sexos nos quartis 3 e 4 e um grande grupo, antes inexistente, passa a pertencer ao segundo quartil de renda (44\% e $52 \%$ de homens e mulheres, respectivamente, envolvidos diretamente na simulação).

Diferente das simulações com as aposentadorias, cuja renda familiar per capita pouco se alterou, a queda na renda familiar dos beneficiários afetados pela redução no valor da pensão é de 7,9\%, para homens, $9,9 \%$, para mulheres, e de, respectivamente, $24,4 \%$ e $26,4 \%$, para os duplo-beneficiários (Tabela 3). As quedas nas rendas individuais também acarretam redução na renda familiar per capita no agregado dos grandes grupos etários: $2,5 \%$ para as idosas que têm redução do valor da pensão; 4,4\% para as duplo-beneficiárias; e 0,3\% e 1\%, respectivamente, para os idosos nessas situações (Tabela 3).

A alteração no duplo benefício também tem efeito negativo e expressivo no aumento do número de pobres: $7,8 \%$ para a população idosa feminina; e 2,1\% para a masculina, como mostra a Tabela 3.

Por outro lado, o efeito destas alterações sobre a redução das despesas do Sistema também seria importante, equivalendo a $3,0 \%$ e $4,8 \%$ do total despendido com aposentadorias e pensões, nas simulações de redução do valor da pensão e do duplo benefício, respectivamente (Tabela 2) (ou $10 \%$ e $13 \%$ da redução total estimada, caso todas as alterações fossem efetuadas).

O duplo benefício, ao mesmo tempo em que pode ser visto como um privilégio, recebido principalmente pelas mulheres, também é extremamente relevante na manutenção da renda necessária para que muitas famílias não se desloquem para abaixo da linha de pobreza. Apesar de não ser socialmente justo que dois benefícios sejam pagos a um mesmo beneficiário e financiados por um mesmo fundo público, a medida merece atenção pelos potenciais efeitos negativos nas rendas médias das mulheres e de suas famílias. Para contornar o problema, países como México, Argentina e Chile, que substituíram os sistemas de 
TABELA 3

Renda de todas as fontes familiar per capita, variação da renda e do percentual de pobres, por sexo e grandes grupos etários, segundo simulação efetuada Brasil - 2006

\begin{tabular}{|c|c|c|c|c|c|c|}
\hline \multirow[t]{2}{*}{ Simulação } & \multicolumn{2}{|c|}{$\begin{array}{l}\text { Beneficiários } \\
\text { afetados }\end{array}$} & \multicolumn{2}{|c|}{$\begin{array}{l}\text { População acima } \\
\text { de } 60 \text { anos }\end{array}$} & \multicolumn{2}{|c|}{$\begin{array}{l}\text { População de } 20 \text { a } \\
59 \text { anos }\end{array}$} \\
\hline & Homens & Mulheres & Homens & Mulheres & Homens & Mulheres \\
\hline \multicolumn{7}{|l|}{ Redução do valor da pensão } \\
\hline $\begin{array}{l}\text { Renda total familiar per capita }(\mathrm{R} \$) \text { antes da } \\
\text { simulação }\end{array}$ & 1.209 & 1.202 & 646 & 675 & 570 & 541 \\
\hline Variação da renda após a simulação (\%) & $-7,9$ & $-9,9$ & $-0,3$ & $-2,5$ & $-0,3$ & $-0,4$ \\
\hline Pobres antes da simulação (\%) & 4,1 & 2,1 & 9,8 & 7,5 & 25,1 & 27,8 \\
\hline Pobres após a simulação (\%) & 5,1 & 2,6 & 9,9 & 7,5 & 25,1 & 27,8 \\
\hline $\begin{array}{l}\text { Aumento no número de pobres (em mil } \\
\text { pessoas) }\end{array}$ & 1,5 & 9,6 & 0,6 & 6,5 & 7,2 & 8,3 \\
\hline \multicolumn{7}{|l|}{ Duplo benefício } \\
\hline $\begin{array}{l}\text { Renda total familiar per capita }(\mathrm{R} \$) \text { antes da } \\
\text { simulação }\end{array}$ & 943 & 950 & 646 & 675 & 570 & 541 \\
\hline Variação da renda após a simulação (\%) & $-24,4$ & $-26,4$ & $-1,0$ & $-4,4$ & 0,0 & $-0,4$ \\
\hline Pobres antes da simulação (\%) & 3,5 & 0,9 & 9,8 & 7,5 & 25,1 & 27,8 \\
\hline Pobres após a simulação (\%) & 12,2 & 6,2 & 10,1 & 8,0 & 25,3 & 28,0 \\
\hline $\begin{array}{l}\text { Aumento no número de pobres (em mil } \\
\text { pessoas) }\end{array}$ & 17,7 & 72,3 & 16,8 & 60,8 & 81,1 & 79,5 \\
\hline \multicolumn{7}{|l|}{$\begin{array}{l}\text { BPC (aumento da idade mínima e redução } \\
\text { do valor do benefício) }\end{array}$} \\
\hline $\begin{array}{l}\text { Renda total familiar per capita }(\mathrm{R} \$) \text { antes da } \\
\text { simulação }\end{array}$ & 335 & 360 & 1,07 & 646 & 675 & 1,04 \\
\hline Variação da renda após a simulação (\%) & $-30,1$ & $-22,5$ & 1,19 & $-0,5$ & $-0,5$ & 1,05 \\
\hline Pobres antes da simulação (\%) & 21,8 & 13,9 & - & 4,1 & 3,3 & \\
\hline Pobres após a simulação (\%) & 30,7 & 19,7 & - & - & - & - \\
\hline $\begin{array}{l}\text { Aumento no número de pobres (em mil } \\
\text { pessoas) }\end{array}$ & 61,0 & 70,9 & & 70,1 & 87,2 & \\
\hline
\end{tabular}

Fonte: Elaboração das autoras.

repartição pelos de capitalização, instituíram que a pensão por morte fosse financiada com recursos familiares (notadamente, com redução da aposentadoria do marido) e não com recursos públicos, para que assim as(os) viúvas(os) pudessem acumular os dois rendimentos. Na comparação com outros países que não adotaram a medida, esta parece ter sido importante na manutenção do nível de renda das mulheres, após as reformas. Apesar de a medida indicar uma saída para o problema, seriam necessários estudos sobre como adaptá-la ao sistema de repartição, em que não há a capitalização das contribuições individuais.

Por fim, a composição da renda total dos BPCs (como são chamados, neste trabalho, os beneficiários do BPC) mostra que o rendimento destas pessoas é quase exclusivamente composto por este benefício. Assim, a elevação da idade mínima para requerê-lo faz com que os beneficiários com idade inferior reduzam drasticamente seus rendimentos totais: $81 \%$ e $92 \%$, para homens e mulheres, respectivamente. Para fins de simplificação, os efeitos desta medida serão mostrados sobre a renda média de todos os beneficiários do BPC e não somente no grupo de 65 a 69 anos, para que sejam diretamente comparáveis aos efeitos da medida de diminuição do valor do benefício. Sobre todos os beneficiários, as reduções nas rendas de idosos e idosas são de, respectivamente, $27,9 \%$ e $29,6 \%$ dos seus rendimentos totais (Tabela. 1).

O decréscimo do valor do BPC para $75 \%$ do salário mínimo (que afeta todos os recebedores do benefício e não somente 
aqueles de 65 a 69 anos) representa, por sua vez, uma queda menor no rendimento médio dos beneficiários, mas maior para as mulheres do que para os homens. Se ambas as medidas fossem implementadas (aumento da idade mínima e redução do valor do benefício), a renda média dos BPCs se reduziria em $41,0 \%$, para os homens, e $46,0 \%$, para as mulheres. Ao se considerar o total de pessoas com 60 anos e mais, no entanto, o efeito das medidas é pequeno e pouco afeta a razão $\mathrm{M} / \mathrm{H}$ (Tabela 1 ).

Sobre o potencial de redução das despesas com benefícios, as duas medidas juntas representariam $0,7 \%$ das despesas totais com aposentadorias e pensões em 2006 , ou $2,3 \%$ do total estimado para a redução das despesas se todas as medidas fossem implementadas.

A análise pela renda familiar per capita mostra que aumentar a idade mínima e reduzir o valor do benefício diminuiria a renda familiar das beneficiárias em $22,5 \%$ e dos beneficiários em 30,1\% (Tabela. 3). Considerando-se o grupo de idosos, as reduções nas rendas seriam fortemente diluídas, mas suficientes para aumentar o número de pobres em $8,9 \%$ e $11,2 \%$, entre homens e mulheres, respectivamente (Tabela 3).

Como já citado, é importante enfatizar que o maior percentual de mulheres beneficiárias estimado neste exercício pode estar supervalorizando as perdas totais de rendimento das mulheres, relativamente aos homens. Por outro lado, o menor contingente de BPCs estimado pode estar subvalorizando a capacidade de redução das despesas com o benefício.

Apesar da inegável importância das alterações no BPC para o incentivo à formalização do trabalho e à transferência de potenciais BPCs para aposentados, a situação menos favorável das mulheres no mercado de trabalho (a despeito dos avanços já apresentados) pode deixá-las de fora do "novo grupo" esperado de aposentados, constituindo um grande grupo de pessoas que não conseguem se aposentar e que também não receberão o BPC até os 70 anos de idade e, portanto, necessitarão de algum outro benefício assistencial. Como consequência, deverá haver piora na relação entre as rendas médias de idosas e idosos.

\section{Conclusões}

Em um sistema de pensão deficitário como a Previdência Social, medidas que reduzam os gastos e que tornem o sistema mais atrativo para seus participantes são urgentes. Se estas medidas visarem o maior ajuste atuarial, restringindo valores ou regras de elegibilidade aos benefícios, certamente reduzirão a renda dos futuros beneficiários, comparativamente àquela que teriam diante das regras atuais. Ajustar o Sistema do ponto de vista orçamentário ou fiscal, tendo como contrapartida a redução da renda dos beneficiários, não é tarefa trivial, além de ser politicamente impopular, mas é necessário para o equilíbrio das contas da Previdência. Neste contexto de ganhos e perdas, em que entram em conflito os papéis de proteção social e justiça atuarial, com limitações orçamentárias, apontar quais e como diferentes grupos seriam afetados é fundamental para subsidiar a tomada de decisões.

De um modo geral, os resultados mostram que as possíveis modificações reduziriam a renda das idosas em comparação à dos idosos, aumentando o diferencial na renda média entre estes dois grupos. No entanto, os resultados também indicam que as diversas alterações propostas têm efeitos de magnitudes diferenciadas sobre cada uma das dimensões analisadas (distribuição de renda e redução de despesas) e, portanto, devem ser ponderadas sob outros critérios, como a natureza do benefício (se é assistencial, ou não), se afeta pessoas em diferentes posições na distribuição de renda e o efeito das medidas também nas rendas familiares dos beneficiários.

Em um sistema atuarialmente justo entre os dois sexos, a paridade entre eles só poderá ser atingida com a igualdade de atuação e remuneração de homens e mulheres no mercado de trabalho. Sem essa igualdade, o desenho de políticas previdenciárias que não considere os diferenciais existentes poderá resultar no aumento indesejado das disparidades de renda entre os sexos na velhice, com maior perda relativa para as mulheres. 


\section{Referências}

ALÉM, A. C.; PASTORIZA, F.; GIAMBIAGI, F. Aposentadoria por tempo de serviço no Brasil: estimativa do subsídio recebido pelos seus beneficiários. [Rio de Janeiro]: BNDES, 1996. Disponível em: <http://www. bndes.gov.br/clientes/federativo/bf_bancos/ e0000169.pdf>. Acesso em: 10 jun. 2009.

BRASIL. Ministério da Previdência Social. Anuário estatístico da previdência social. Brasília: ACS/MPS; DIIE/Dataprev, 2007.

BRASIL. Tábuas Completas de Mortalidade - 2007. 2007b. Disponível em: <http://www. ibge.gov.br/home/estatistica/populacao/ tabuadevida/2007/default.shtm $>$. Acesso em: 11/10/2010.

BRASIL. Ministério da Previdência Social. Regime geral de previdência social: balanço do ano de 2008. Informe de Previdência Social, Brasilia, v. 21, n. 1, p. 1-16, jan. 2009.

CAETANO, M. A. Determinantes da sustentabilidade e do custo previdenciário: aspectos conceituais e comparações. Brasília: Ipea, 2006. (Texto para discussão, 1.226).

CAMARGO, J. M.; REIS, M. C. Lei Orgânica da Assistência Social: incentivando a informalidade. In: TAFNER, P.; GIAMBIAGI, F. (Orgs.). Previdência no Brasil: debates, dilemas e escolhas. Rio de Janeiro: Ipea, 2007, cap. 7 .

FERNANDES, F. Sistema previdenciário e desigualdades inter e intrageracionais no Brasil: o papel da dinâmica demográfica. Previdência em Dados.1994.

GIAMBIAGI, F. As muitas reformas da previdência social. Rio de Janeiro: PUC-Rio, Departamento de Economia, 2000. (Texto para discussão, 430). Disponível em: <http://www.econ.puc-rio.br/pdf/td430. pdf>. Acesso em: 14 jul. 2009.

GIAMBIAGI, F. et al. Diagnóstico da previdência social no Brasil: o que foi feito e o que falta reformar? Rio de Janeiro: Ipea. (Texto para Discussão, 1.050). Disponível em: <http://www.ipea.gov.br/082/08201008. jsp?ttCD_CHAVE=2120>. Acesso em: 25 abr. 2011.
GIAMBIAGI, F. et al. Impacto de reformas paramétricas na previdência social brasileira: simulações alternativas. Rio de Janeiro: Ipea, 2007. (Texto para discussão, 1.289).

GIAMBIAGI, F.; TAFNER, P. Uma agenda parcial de reformas para 2009: à procura de um "pacto de Toledo" brasileiro. Rio de Janeiro: Ipea, 2007b. (Texto para discussão, 1.299). Disponível em: <http://www.ipea. gov.br/sites/000/2/publicacoes/tds/td_1299. pdf $>$. Acesso em: 14 jul. 2009.

LAVINAS, L.; DAIN, S. Proteção social e justiça redistributiva: como promover a igualdade de gênero. Rio de Janeiro: UFRJ, 2005. Disponível em:<http://www.ie.ufrj. br/aparte/pdfs/versao_final_texto_lena_e_ sulamis.pdf?PHPSESSID $=\overline{5} 3937 \overline{5}$ efc5acf 4b47ec4b92462e0c145>. Acesso em: 14 jul. 2009.

MARRI, I. G. Reforma de Previdência Social: simulações e impactos sobre os diferenciais de gênero. Tese (Doutorado). Belo Horizonte: Cedeplar/Universidade Federal de Minas Gerais, 2009. Disponível em: <http://www.cedeplar.ufmg.br/pos-em-demografia/teses-2009/reforma-de-previdencia-social-simulacoes-e-impactos-sobre-os-diferenciais-de-genero.php $>$. Acesso em: 02 abr. 2010.

NEVES, R. Z. Regras de concessão do BPC nos desincentivos à contribuição individual para o regime previdenciário. 2008. Monografia (Graduação). Belo Horizonte: Faculdade de Ciências Econômicas/ Universidade Federal de Minas Gerais, 2008.

ROCHA, R.; CAETANO, M. O sistema previdenciário brasileiro: uma avaliação de desempenho comparada. Brasilia: Ipea, 2008. (Texto para discussão, 1.331).

SOCIAL SECURITY ADMINISTRATION SSA. Widows, widowers \& other survivors. 2008. Disponível em: <http://www.ssa.gov/ ww\&os2.htm > . Acesso em: 19 set. 2008.

SORJ, B. Trabalho e responsabilidades familiares: um estudo sobre o Brasil. ILO, Geneva: UFRJ, 2005. 
TAFNER, P. Simulando o desempenho do sistema previdenciário e seus efeitos sobre pobreza sob mudanças nas regras de pensão e aposentadoria. Rio de Janeiro: Ipea, 2007. (Texto para discussão, 1.264). Disponível em: <http://www.ipea.gov.br/ sites/000/2/publicacoes/tds/td_1264.pdf > . Acesso em: 14 jul. 2009.

TURRA, C.; MARRI I. G.; WAJNMAN, S. Os argumentos de proteção social e eqüidade individual no debate sobre previdência e gênero no Brasil. Mudança populacional: aspectos relevantes para a Previdência. Brasília: Ministério da Previdência Social, 2008. Disponível em: < http:// www.previdenciasocial.gov.br/arquivos/ office/3_081208-173355-270.pdf > . Acesso em: 02 abr. 2010.

WORLD BANK. Brazil social insurance and private pensions. Report 12336-BR. Country Operations Division, Country Department I, Latin America and the Caribbean Region. 1995. Disponível em: <http:// www-wds.worldbank.org/external/default/ WDSContentServer/WDSP/IB/1995/01/25/0 00009265_3961005074921/Rendered/PDF/ multi_page.pdf $>$. Acesso em: 25 out. 2010.

ZYLBERSTAJN, H.; AFONSO, L. E.; SOUZA, A. P. Reforma da previdência social e custo de transição: simulando um sistema universal para o Brasil. [S.I.], 2005.

\section{Resumen}

Reforma de la Seguridad Social: simulaciones e impactos sobre los diferenciales de sexo

Las mujeres reciben de media, como reflejo de su actuación diferenciada en el mercado de trabajo (marcada por la menor actividad económica y menores salarios), jubilaciones menores que los hombres, aunque son las principales receptoras de pensiones por viudedad y son la mayoría de las beneficiarias del BPC. Asimismo, cuanto menor beneficio de media reciben, mayor es la dependencia económica relativa de las ancianas de los beneficios de jubilación y de los ingresos de otros miembros de la familia en que viven. El presente trabajo busca verificar cómo posibles modificaciones en las reglas de elegibilidad de jubilaciones, pensión por muerte y BPC, frecuentemente mencionadas como necesarias por especialistas para el equilibrio presupuestario del Sistema de Seguridad Social brasileño, pueden afectar a las iniquidades de renta entre los sexos en la vejez, incorporando una dimensión relevante más para la evaluación de las propuestas de reforma del sistema.

Palabras-clave: Seguridad Social. Desigualdad de renta. Género.

\section{Abstract \\ Reform of the Brazilian Social Security System: simulations and impacts on differences between the sexes}

Today, average retirement benefits in Brazil are lower for women than for men, but women are the main pension receivers (usually due to the death of their husbands). Women also make up the majority of the beneficiaries of the Brazilian social Security. These facts are certainly reflections of women's earnings while working (they usually work less and earn less on the labor market). At the same time that they receive lower average benefits, older women are more economically dependent on social security benefits and on the earnings of other members of their families. The present article consists of an investigation into possible changes in the rules on eligibility for receiving retirement and pension benefits due to death. Such changes are frequently mentioned by specialists as necessary in order to balance the Brazilian Social Security budget. To this end, the author discusses how changes may affect the inequalities in income between 
the sexes in old age and thus bring in a further important dimension in evaluating proposals for reforming the system.

Keywords: Social security. Inequality of income. Gender.

Recebido para publicação em 17/07/2010

Aceito para publicação em 27/10/2010 